\title{
Effects of alterations in the immunocompetent status of Mus musculus females on the survival of transferred Mus caroli embryos
}

\author{
B. A. Croy*, J. Rossant* $†$ and D. A. Clark $\dagger$ \\ *Department of Biological Sciences, Brock University, St. Catharines, Ontario L2S 3A1, and \\ $\dagger$ Departments of Medicine and Pathology, McMaster University Medical Centre, McMaster \\ University, Hamilton, Ontario L8N $3 Z 5$ Canada
}

\begin{abstract}
Summary. The role of the immune system in promoting the midterm death of Mus caroli embryos transferred to the Mus musculus uterus was studied in vivo by transferring $M$. caroli blastocysts to recipients with altered immune status. Transfers of embryos to chimaeric mothers (Mus musculus $\leftrightarrow$ Mus caroli), which were expected to be tolerant of species antigens, resulted in survival of $M$. musculus embryos but death of $M$. caroli embryos. The preferential survival of $M$. musculus embryos was explained by showing that $M$. musculus embryos can survive in the $M$. caroli uterus. Transfers to $\mathrm{T}$ celldeficient mice of genotype $n u / n u$ and to NK cell-deficient mice of genotype $b g / b g$ as well as treatment of normal transfer recipients with Cyclosporin A or anti-Ia antiserum failed to prolong survival. However, immunization of recipients with $M$. caroli lymphocytes promoted more rapid and uniform failure of the interspecies pregnancy. Cytotoxic cells were detected in the resorbing embryos on Day 10.5 in immune pregnancies and on Day 12.5 in non-immune pregnancies and these cells were promiscuous in their pattern of lysis, showing equal reactivity against $M$. caroli, transfer recipient and 3 rd party target cells. These experiments show that failure of $M$. caroli embryos in the $M$. musculus uterus is complex, but probably does not involve responses by classical cytotoxic T lymphocyte or natural killer cell pathways. Participation of the immune system in the resorption process, however, is confirmed and is associated with generation of promiscuous cytolytic cells.
\end{abstract}

\section{Introduction}

Successful gestation of the semi-allogeneic fetus has remained a paradox in transplantation biology (Beer \& Billingham, 1976). To further understanding of the mechanisms normally involved in successful pregnancy, we have developed a rodent embryo-transfer system in which consistent midterm failure of pregnancy occurs with apparent involvement of maternal immune reactivity against the fetus (Croy, Rossant \& Clark, 1982). Xenogeneic embryos from females of the mouse species Mus caroli, when placed in the uterus of pseudopregnant females of the species $M$. musculus, implant and grow normally until mid-gestation and then resorb. The resorbing embryos are infiltrated by cytolytic cells expressing T-cell lineage markers (CTL). Furthermore, non-specific suppressor cells, usually associated with successful pregnancies, are absent from the decidua of the $M$. caroli conceptuses before death (Clark, Slapsys, Croy \& Rossant, 1983). Other experiments have shown that matching the genotype of the trophoblast to that of the foster mother will rescue the $M$. caroli embryos (Rossant, Mauro \& Croy, 1982; Rossant, Croy, Clark \& Chapman, 1983), suggesting that failure of $M$. caroli trophoblast to recruit suppressor cells may allow access of CTL to the fetus, causing death. None of these experiments proves, however, that absence of suppression and appearance of CTL are the sole factors determining $M$. caroli death. This could 
only be proved by successful gestation of $M$. caroli embryos in recipients unable to generate a cytotoxic response against the embryos. We have attempted to define the contribution of the immune system to the death of $M$. caroli embryos by assessing intrauterine viability of $M$. caroli embryos in putatively tolerant, immunodeficient and immunized animals.

\section{Materials and Methods}

Mice. The $M$. caroli mice were bred at Brock University as a random stock; $M$. musculus animals included C57BL/6-bg/bg mice, a gift from Dr. R. Swank, Roswell Park Memorial Institute, Buffalo, NY, U.S.A., C3H/HeJ and DBA/2J mice purchased from Jackson Laboratories, Bar Harbor, ME, U.S.A., and CDl and CD1-nu/nu mice purchased from Charles River Laboratories, St Constant, Quebec. Aggregation and blastocyst injection chimaeras were made between $M$. caroli and $M$. musculus of the CD1 strain as previously described (Rossant et al., 1982) and are designated $M$. caroli $\leftrightarrow M$. musculus chimaeras. Transferred $\boldsymbol{M}$. musculus blastocysts were always of the CD1 genotype and CD1 females were used as recipients unless otherwise indicated. All mice were housed under standard conditions except for the nude mice which were caged under filter caps with sterilized food, water and bedding and housed in rooms remote from other animals. Mice were used between 6 and 14 weeks of age.

Immunization of $M$. musculus females. CDI females, 6 weeks of age, were each injected intraperitoneally (i.p.) with $10^{7}$ irradiated splenocytes from $M$. caroli animals and given booster injections twice at 2 -week intervals. After an additional 3 weeks, these mice were used as embryo transfer recipients.

Skingrafting. Female $n u / n u$ and male $M$. caroli $\leftrightarrow M$. musculus chimaeras were grafted bilaterally in the thoracic region with tail skin from females of the $M$. caroli and $M$. musculus species. Graft sites were covered with plaster casts for 1 week, then uncovered and scored daily for necrosis and sloughing.

Collection of embryos. Blastocyst stage embryos were collected from the uteri of $M$. musculus females 3.5 days after detection of vaginal plugs following natural matings. The morning of plug detection was designated Day 0.5 of pregnancy. Hormone stimulation was used to obtain blastocysts from $M$. caroli females; $2 \cdot 5$ i.u. PMSG (Sigma, St Louis, MO, U.S.A.) was administered i.p. followed $48 \mathrm{~h}$ later by $2 \cdot 5$ i.u. hCG (Sigma). Blastocysts were recovered from the uterus $74-76 \mathrm{~h}$ after hCG injection. Mice were killed by cervical dislocation and the uteri dissected and flushed with PB 1 medium (Whittingham \& Wales, 1969) plus $10 \%$ fetal calf serum (FCS) to recover the blastocysts. Blastocysts were transferred to the uteri of pseudopregnant mice within $2 \mathrm{~h}$ of collection.

Embryo transfers and laparotomy. All recipient females, except $M$. caroli, were selected for oestrus and placed with vasectomized $M$. musculus males. Embryo transfers were performed 2.5 days after detection of a vaginal plug. $M$. caroli females were given $2 \cdot 5$ i.u. PMSG followed $48 \mathrm{~h}$ later by $2.5 \mathrm{i} . \mathrm{u} \mathrm{hCG}$ and then paired with vasectomized $M$. caroli males or cervically stimulated by a glass rod for $120-300 \mathrm{sec}, 14 \mathrm{~h}$ after hCG treatment. Because most $M$. caroli $\times M$. caroli matings do not result in vaginal plug formation, it was usually not known if the hormone-primed, paired $M$. caroli females were truly pseudopregnant. $M$. caroli females were used as recipients $50-56 \mathrm{~h}$ after hCG.

Recipients were anaesthetized with tribromoethanol (Green, 1975) administered i.p. and 2-7 blastocysts of $M$. caroli or $M$. musculus genotype were placed in each uterine horn. To assess the success of pregnancy, mice were anaesthetized 9-19 days after transfer and laparotomy was performed through a midline abdominal incision. Both uterine horns were exteriorized and examined for the location of viable and resorbing embryos. Pregnancy failure after laparotomy was 
difficult to interpret due to the added factors of surgical trauma and anaesthetic depression, but viable $M$. musculus young were born to many recipients after laparotomy.

Cyclosporin A treatment. Cyclosporin A, kindly given by Dr J. F. Borel, Sandoz, Basel, Switzerland, was dissolved in medium-chain triglycerides and administered at doses between 7.5 and $100 \mathrm{mg} / \mathrm{kg}$. Subcutaneous (s.c.) or i.p. injections were given once daily beginning on the day of embryo transfer.

Treatment with anti-Ia ${ }^{k}$. Anti-Ia ${ }^{\mathrm{k}}$ monoclonal antibody ascitic fluid was a gift from Dr T. G. Wegmann, University of Alberta (Clone 10-3.6, Salk Cell Distribution Center, San Diego, CA, U.S.A.). $\mathrm{C} 3 \mathrm{H} / \mathrm{HeJ}$ females that had been successfully mated by vasectomized males were anaesthetized on the morning of plug detection and slowly injected intravenously with ascitic fluid containing $0.5 \mathrm{mg}$ specific IgG. Treated females received embryo transfers 2 days later. Blood samples were collected from the retro-orbital sinus of anaesthetized mice before treatment and at various stages thereafter. These samples were diluted in leucocyte counting fluid and counted, using a haemocytometer, to monitor the effects of the antiserum treatment.

Chromium-51 release assay. Uteri containing resorbing $M$. caroli embryos were dissected from either immune or nonimmune CDl females and single cell suspensions were prepared by passing the resorbing tissue through a 60 -mesh stainless-steel screen into alpha minimum essential media (MEM) (Gibco, Grand Island, NY, U.S.A.) supplemented by $10 \%$ FCS, 100 i.u. penicillin $/ \mathrm{ml}, 0.05$ $\mathrm{mg}$ streptomycin/ml, $10^{-5} \mathrm{M}$-2-mercaptoethanol and $20 \mathrm{~mm}$-Hepes. The cell suspensions were layered over Lympholyte M (Cedarlane Laboratories, Hornby, Ontario) and centrifuged, and the interface cells were collected, washed and tested for their ability to lyse a variety of ${ }^{51} \mathrm{Cr}$-labelled target cells. Target cells included Con-A-induced lymphoblasts of $M$. caroli, CD1, C3H/HeJ and DBA/2J origin, P815 cells or YAC cells. The targets were labelled for $90 \mathrm{~min}$ with $0.5 \mathrm{ml} \mathrm{Na}{ }^{51} \mathrm{CrO}_{4}$ (sp. act. $1 \mathrm{mCi} / \mathrm{ml}$; New England Nuclear, Boston, MA, U.S.A.), washed well and $3 \times 10^{3}$ target cells were co-incubated in $200 \mu \mathrm{l}$ supplemented MEM in microtest plate wells with effector cells from the resorbing embryos. Effector:target cell ratios $(E: T)$ were $10: 1$ or $15: 1$. Spontaneous release was determined from control cultures containing effector cells derived from age-matched normal CD1 embryos. After incubation for $6 \mathrm{~h} 100 \mu$ l supernatant were removed from each culture and counted for isotope release in a Philips 4800 series gamma counter. The percentage specific chromium release was determined from the standard formula: (test c.p.m. - spontaneously released c.p.m.) $/(\mathrm{NP} 40$ released c.p.m. - spontaneously released c.p.m.) $\times 100 \%$.

\section{Results}

Embryo transfer to $\mathrm{M}$. caroli females

A series of transfers into $M$. caroli recipients was performed to establish whether (1) $M$. caroli blastocysts could ever survive to term after embryo transfer manipulations and (2) embryo failure was reciprocal between the two species. Embryo transfers to $M$. caroli females were not very successful; 7 pregnancies resulted from a series of 32 transfers (Table 1). Successful pregnancy occurred only in females rendered receptive by pairing to vasectomized $M$. caroli males. Transfers to $3 / 8$ females showing copulatory plugs and $4 / 16$ females not showing plugs resulted in implantation. No implantation occurred in $8 / 8$ females stimulated by a glass rod. In one female, embryos of both species implanted but failed early and this recipient was excluded from the table as she almost certainly represented generalized, non-specific failure to maintain pregnancy. It is clear that $M$. caroli embryos can survive to term after embryo handling and transfer procedures (Mouse 5). This has not been demonstrated previously and shows that failure of $M$. caroli embryos in the $M$. musculus uterus is a biological problem and not a transfer artefact. Also, development of $M$. musculus embryos proceeds further in the $M$. caroli uterus than in the reciprocal transfers; all $M$. 
Table 1. Bilateral embryo transfers to $M$. caroli recipients

\begin{tabular}{|c|c|c|c|c|c|c|c|}
\hline \multirow{2}{*}{$\begin{array}{l}\text { Recipient } \\
\text { number }\end{array}$} & \multirow{2}{*}{$\begin{array}{c}\text { Gestational } \\
\text { age at } \\
\text { laparotomy (days) }\end{array}$} & \multicolumn{3}{|c|}{ M. musculus embryos } & \multicolumn{3}{|c|}{$M$. caroli embryos } \\
\hline & & Transferred & Implanted & Status & Transferred & Implanted & Status \\
\hline 1 & $10 \cdot 5$ & 4 & 3 & Alive & 4 & 3 & Alive \\
\hline 2 & 11.5 & 3 & 1 & Alive & 3 & 1 & Alive \\
\hline 3 & 11.5 & 3 & 0 & & 3 & 2 & Alive \\
\hline 4 & $15 \cdot 5$ & 4 & 1 & Dying & 3 & 0 & \\
\hline 5 & $15 \cdot 5$ & 3 & 0 & & 4 & 4 & Live born \\
\hline 6 & $18 \cdot 5^{*}$ & 2 & 1 & Dead & 0 & & \\
\hline
\end{tabular}

* Gestation in $M$. caroli is 17.5 days.

musculus embryos were well formed and showed no signs of resorption. As gestation of $M$. caroli is $17 \cdot 5$ days (Frels, Rossant \& Chapman, 1980) it is difficult to know whether the single very large embryo observed in recipient No. 6 on Day 18.5 represents embryonic failure or dystocia. These studies led us to predict that $M$. musculus embryos would survive in interspecific chimaeras, whether or not embryonic failure was mediated by immunological mechanisms.

Transfer of M. caroli and M. musculus blastocysts to female M. caroli $\leftrightarrow$ M. musculus chimaeras

If immune rejection is the sole cause of death of $M$. caroli embryos gestating in the $M$. musculus uterus, then transfer of $M$. caroli to immunologically unresponsive hosts would be expected to prolong their survival. We have been unsuccessful in producing xenogenic tolerance to $M$. caroli in $M$. musculus females by using a variety of protocols that do not require host irradiation (Brent, Hansen, Kilshaw \& Thomas, 1973; Streilein \& Gruchalla, 1981; Chutna, Holan \& Hasek, 1981) and therefore elected to produce embryonic chimaeras by blastocyst injection (Rossant \& Frels, 1980) or aggregation of morulae (Rossant et al., 1982) and to test any resulting female animals (probability of an XX $\times$ XX chimaeric female is $1 / 4$ ) for their ability to gestate embryos of $M$. caroli and $M$. musculus. Previous studies of intraspecific chimaeras have shown that such animals are tolerant of both component genotypes (Mintz \& Silvers, 1967; Phillips \& Wegmann, 1973; Matsunaga, Simpson \& Meo, 1980). Table 2 reports the results of successful transfers to 9 chimaeric mice. Viable embryos were found in $34 / 36 \mathrm{M}$. musculus implantation sites examined at laparotomy.

Table 2. Embryo transfer to $M$. caroli $\leftrightarrow M$. musculus blastocyst injection and aggregation chimaeras

\begin{tabular}{|c|c|c|c|c|c|c|c|c|}
\hline \multirow[b]{2}{*}{$\begin{array}{l}\text { Recipient } \\
\text { number* }\end{array}$} & \multirow{2}{*}{$\begin{array}{l}\% \\
M . \text { caroli } \\
\text { coat } \\
\text { colour }\end{array}$} & \multirow{2}{*}{$\begin{array}{l}\text { Gestational } \\
\text { age at } \\
\text { laparotomy } \\
\text { (days) }\end{array}$} & \multicolumn{3}{|c|}{$M$. caroli embryos } & \multicolumn{3}{|c|}{ M. musculus embryos } \\
\hline & & & Transferred & Implanted & $\begin{array}{c}\text { Live } \\
\text { fetuses }\end{array}$ & Transferred & Implanted & $\begin{array}{c}\text { Live } \\
\text { fetuses }\end{array}$ \\
\hline $1+$ & 60 & $10 \cdot 5$ & 4 & 4 & 2 & 3 & 3 & 3 \\
\hline 2 & 40 & $12 \cdot 5$ & 5 & 5 & 0 & 6 & 6 & 6 \\
\hline 3 & 55 & $12 \cdot 5$ & 7 & 6 & 0 & 6 & 3 & 3 \\
\hline 4 & 50 & $13 \cdot 5$ & 4 & 4 & 1 & 5 & 5 & 3 \\
\hline 5 & 5 & $14 \cdot 5$ & 6 & 6 & 0 & 6 & 5 & 5 \\
\hline 6 & 70 & $14 \cdot 5$ & 7 & 7 & 4 & 6 & 5 & 5 \\
\hline 7 & 50 & $17 \cdot 5$ & 5 & 4 & 0 & 5 & 5 & 5 \\
\hline 8 & 40 & $19 \cdot 5$ & 4 & 4 & 0 & 5 & 4 & 4 \\
\hline Totals & & & 42 & 40 & 7 & 42 & 36 & 34 \\
\hline
\end{tabular}

* An additional $M$. caroli $\leftrightarrow M$. musculus aggregation chimaera, 50\% $M$. caroli by coat colour, received $11 M$. musculus embryos only and produced liveborn offspring.

$\uparrow$ Aggregation chimaera, all others were blastocyst injection chimaeras. 
One litter was liveborn, as predicted. However, amongst $40 \mathrm{M}$. caroli implantation sites only 7 live embryos were found. None of the viable $M$. caroli embryos proceeded to term but we could not determine whether this was a consequence of laparotomy or primary embryo failure. The two animals judged to have the highest percentage of $M$. caroli contribution by coat colour contained the largest number of viable $M$. caroli fetuses. A sufficient number of $M$. caroli embryos resorbing in chimaeras was never available at one time to determine whether cytotoxic cells were actually present in these presumed tolerant recipients and it remains possible that the interspecies chimaeras are not species tolerant, although this seems unlikely.

To estimate the level of tolerance achieved in the interspecies chimaeras, 10 phenotypically male $M$. caroli $\leftrightarrow M$. musculus chimaeras were grafted with skin from female $M$. caroli and CD1 mice. Of the 20 grafts, 18 were technically successful and the majority of these failed $2-4$ weeks after grafting. Only $1 / 10 \mathrm{M}$. caroli grafts and $2 / 8 \mathrm{M}$. musculus grafts were accepted indefinitely. Because the $M$. caroli animals are random bred and grafts exchanged between individuals of this species are generally unsuccessful (B. A. Croy, unpublished) and CD1 mice are also random bred, skin graft rejection probably results from recognition of allogeneic differences. Due to these allogeneic responses, we were unable to demonstrate that successful xenogeneic tolerance had been established. However, recognition of allogeneic differences does not regularly lead to embryonic failure in intraspecies pregnancies and is thus unlikely to explain the loss of $M$. caroli embryos in chimaeras displaying xenogeneic tolerance.

\section{Transfer of M. caroli embryos to immunologically deficient $\mathbf{M}$. musculus females}

Transfers to mice receiving Cyclosporin A. An alternative host to one specifically unresponsive to $M$. caroli, in which the role of the immune system can be examined, is one which has a broad immune deficiency. As cytotoxic cells of the $\mathrm{T}$ lineage have been detected in resorbing $M$. caroli embryos (Croy et al., 1982), treatment of the embryo transfer recipients with Cyclosporin A, an effective immunosuppressant that predominantly inhibits primary $T$ lymphocyte-dependent immune responses (Bunjes et al., 1982) and is capable of inducing transplantation tolerance across major histocompatibility differences (Borel, Feurer, Magnee \& Stahelin, 1977; White, Plumb, Pawelec \& Brons, 1979) might prolong survival of $M$. caroli embryos. Six $M$. musculus females received transfers of $M$. caroli embryos to one uterine horn and $M$. musculus embryos to the opposite horn plus various doses of Cyclosporin A beginning on the day of transfer (i.e. 2 days before implantation) and continuing daily thereafter until laparotomy. Low doses of Cyclosporin A failed to prolong the gestation of $M$. caroli embryos while $M$. musculus fetuses remained viable (Table 3). High drug doses adversely affected the survival of all embryos. Embryotoxicity has been reported for comparable doses of Cyclosporin A in the rat and rabbit (Ryffel, 1982). M. caroli resorption sites present in animals receiving 7.5 and $15 \mathrm{mg}$ Cyclosporin $\mathrm{A} / \mathrm{kg}$ were 2-3 times larger than over 500 sites examined in untreated animals. The large resorption sites were black and necrotic and

Table 3. Embryo transfer to $M$. musculus females treated with Cyclosporin A

\begin{tabular}{|c|c|c|c|c|c|c|c|c|}
\hline \multicolumn{2}{|c|}{ Cyclosporin A } & \multirow{2}{*}{$\begin{array}{l}\text { Gestational } \\
\text { age at } \\
\text { laparotomy } \\
\text { (days) }\end{array}$} & \multicolumn{3}{|c|}{ M. caroli embryos } & \multicolumn{3}{|c|}{ M. musculus embryos } \\
\hline Dose $(\mathrm{mg} / \mathrm{kg})$ & Route & & Transferred & Implanted & Alive & Transferred & Implanted & Alive \\
\hline $7 \cdot 5$ & s.c. & $11 \cdot 5$ & 4 & 4 & 0 & 4 & 4 & 4 \\
\hline $15 \cdot 0$ & s.c. & $11 \cdot 5$ & 4 & 4 & 0 & 4 & 4 & 3 \\
\hline $22 \cdot 5$ & s.c. & $11 \cdot 5$ & 5 & 4 & 0 & 5 & 5 & 4 \\
\hline $22 \cdot 5$ & i.p. & $11 \cdot 5$ & 4 & 4 & 0 & 5 & 5 & 2 \\
\hline $50 \cdot 0$ & s.c. & $12 \cdot 5$ & 6 & 6 & 0 & 4 & 4 & 0 \\
\hline $100 \cdot 0$ & s.c. & $11 \cdot 5$ & 5 & 5 & 0 & 4 & 4 & 0 \\
\hline
\end{tabular}


contained no evidence of organized embryonic tissue, suggesting that some impairment of the embryo resorption process occurred in the presence of the drug. Inhibition of immune responses by Cyclosporin A treatment, however, could not prevent failure of $M$. caroli embryos.

Transfer of $\mathrm{M}$. caroli embryos to recipients treated with anti-Ia antiserum. As a variety of inflammatory cells are associated with $\mathrm{T}$ cells in rejecting allografts (Ascher, Ferguson, Hoffman \& Simmons, 1979), we also depleted lymphocytes in a less class-specific manner by treatment of embryo transfer recipients with anti-Ia antiserum. It is known that Ia is expressed on B cells and macrophages as well as on some T cells (McDevitt, Delovitch \& Press, 1977) and that treatment with anti-la antiserum in vivo can inhibit macrophage-T cell interactions during antigen presentation (Perry \& Green, 1982), deplete B cells from the circulation and lymphoid tissues (Waldor et al., 1984) and promote semiallogeneic bone marrow graft success in non-irradiated recipients (Francescutti, Gambel \& Wegmann, 1983). C3H/HeJ females were given anti-Ia ${ }^{k}$ antibody on Day 0.5 of pseudopregnancy and received bilateral transfers of $\mathrm{C} 3 \mathrm{H}$ and $M$. caroli embryos on Day 2.5 . Antiserum treatment severely depleted the circulating leucocyte pool and, even by term, the mice had less than one third of their normal leucocyte count; yet no $M$. caroli embryos survived to Day 12.5 of pregnancy (Table 4). The effects of antiserum treatment, however, are compatible with successful gestation as liveborn $\mathrm{C} 3 \mathrm{H}$ offspring were obtained. Therefore, the lymphopenia associated with infusion of anti-Ia antiserum does not prolong gestation of $M$. caroli embryos in the $M$. musculus uterus.

Table 4. Embryo transfer to $\mathrm{C} 3 \mathrm{H}$ females treated with anti-Ia ${ }^{\mathrm{k}}$ antibody

\begin{tabular}{|c|c|c|c|c|c|c|c|c|c|}
\hline \multirow{2}{*}{$\begin{array}{l}\text { Recipient } \\
\text { number }\end{array}$} & \multicolumn{3}{|c|}{ M. caroli embryos } & \multicolumn{3}{|c|}{$\mathrm{C} 3 \mathrm{H}$ embryos } & \multicolumn{3}{|c|}{$\%$ leucocyte decrease* } \\
\hline & Transferred & Implanted & Alive $\dagger$ & Transferred & Implanted & Alive & Day 2 & Day 12 & Day 21 \\
\hline 1 & 7 & 2 & 0 & 4 & 4 & $4 \ddagger$ & $88 \cdot 3$ & 83.9 & $66 \cdot 6$ \\
\hline 2 & 7 & 2 & 0 & 4 & 4 & $3 \S$ & $95 \cdot 1$ & $64 \cdot 2$ & 63.4 \\
\hline
\end{tabular}

* Leucocyte count on Day 0 , before infusion with anti-la ${ }^{k}$ antibody, used for normalizations.

$\uparrow$ Both recipients were examined by laparotomy on Day 12.5 of gestation.

$\ddagger 3$ full-term offspring born.

$\S$ Aborted on Day 18 of gestation, after laparotomy.

Transfer of M. caroli embryos to genetically immunodeficient mice. Broad immunodeficiencies can result from specific genetic mutations as well as from pharmacological intervention. Mice of the $n u / n u$ genotype are athymic (Pantelouris, 1968) and unable to reject many types of allografts and xenografts (Manning, Reed \& Schaffer, 1973). M. caroli embryos transferred to such mice should therefore not be infiltrated by cytotoxic $T$ cells and the pattern of embryo survival should establish whether such an occurrence is necessary for failure of the xenogeneic pregnancies. The results of a series of such transfers are presented in Table 5 and show that survival of $M$. caroli embryos was not prolonged following implantation in the $\mathrm{T}$ cell-deficient mice.

To assess the level of impairment of $n u / n u$ mice to $M$. caroli xenoantigens, $7 n u / n u$ females were grafted with tail skin from $M$. caroli females. All 7 grafts survived indefinitely (30-45 days) until the mice were killed for other experiments, which suggests that $n u / n u$ mice have no immune effector mechanism to deal with tissue grafts of $M$. caroli origin. It remains possible, however, that the mechanisms for skin graft rejection and embryo rejection differ and that $n u / n u$ mice are competent in the latter. To sustain this view, it is necessary to postulate that neither cytolytic $T$ lymphocytes nor DTH-mediated responses effect the death of $M$. caroli embryos, but that other defence mechanisms present in $n u / n u$ mice, such as NK cells, antibody-mediated responses or activated macrophages (Kindred, 1979; Sharp \& Colston, 1984) are important. Difficulties in obtaining 
Table 5. Transfer of $M$. caroli embryos to genetically immunodeficient recipients

\begin{tabular}{|c|c|c|c|c|c|c|c|}
\hline \multirow{2}{*}{$\begin{array}{l}\text { Recipient } \\
\text { genotype }\end{array}$} & \multirow{2}{*}{$\begin{array}{c}\text { Gestational } \\
\text { age at } \\
\text { laparotomy (days) }\end{array}$} & \multicolumn{3}{|c|}{$M$. caroli embryos } & \multicolumn{3}{|c|}{ M. musculus embryos } \\
\hline & & Transferred & Implanted & Alive & Transferred & Implanted & Alive \\
\hline$n u / n u$ & $12 \cdot 5$ & 10 & 4 & 0 & & & \\
\hline$n u / n u$ & 12.5 & 6 & 6 & 0 & 5 & 3 & 3 \\
\hline$n u / n u$ & $19 \cdot 5$ & 4 & 1 & 0 & 4 & 4 & 4 \\
\hline$n u / m u$ & Term & 4 & 4 & 0 & 5 & 4 & 4 \\
\hline$n u / n u$ & Term & 4 & 2 & 0 & 5 & 5 & 5 \\
\hline$b g / b g$ & 11.5 & 5 & 1 & 0 & & & \\
\hline$b g / b g$ & 11.5 & 4 & 1 & 0 & & & \\
\hline$b g / b g$ & $13 \cdot 5$ & 5 & 3 & 0 & & & \\
\hline
\end{tabular}

regular oestrous cycles in $n u / n u$ mice and in maintaining successful pregnancies of transferred $M$. musculus embryos in these recipients even with progesterone supplementation and ovarian transplantation (B. A. Croy, unpublished) have limited our studies of these possible mechanisms.

To test for the role of NK cells in mediating death of $M$. caroli embryos, we transferred $M$. caroli blastocysts to recipients of $b g / b g$ genotype. Beige mice are known to have a complete and selective deficiency in NK cells, but their other forms of cell-mediated immunity appear completely normal (Roder \& Duwe, 1979). The immune deficiency of these recipients was confirmed by demonstrating that their spleen cells were not able to lyse YAC target cells (data not shown). These embryo transfers failed (Table 5) suggesting that NK cells are unlikely to play a major role in initiating the death of $M$. caroli embryos in the $M$. musculus uterus.

\section{Immunization of recipients does alter the pattern of $\mathrm{M}$. caroli embryo survival}

As we had been unable to prolong survival of $M$. caroli embryos in immunologically impaired animals, we considered whether prior immunization of mice with $M$. caroli lymphoid tissue would alter the pattern of survival of $M$. caroli embryos after transfer. $M$. musculus (CD1) females received 3 doses of $M$. caroli splenocytes 2 weeks apart before being used as embryo transfer recipients. Transfer of $M$. caroli embryos to immune recipients significantly changed the resorption pattern (Text-fig. 1). All embryos were resorbed by Day 10.5 of gestation, eliminating the variability in both the frequency and the timing of resorption seen in non-immune females. Immunization therefore resulted in a more rapid and more consistent failure of $M$. caroli embryos. These results demonstrate that the immune system is indeed an active participant in the death and resorption process following xenogeneic embryo transfer in the mouse.

\section{Cytotoxic cells are present in $\mathrm{M}$. caroli embryos resorbing in immunized mice}

In a previous series of experiments, we reported that cytotoxic cells could be isolated from $M$. caroli embryos resorbing in unimmunized $M$. musculus between 11.5 and 13.5 days of gestation, with the peak of reactivity against $M$. caroli Con A lymphoblast targets occurring on Day 12.5 (Croy et al., 1982). To confirm participation of the immune system in the death of $M$. caroli embryos in immunized mice, we examined cells isolated earlier in pregnancy for their ability to lyse $M$. caroli, CD1 and 3rd party lymphoblast targets. Cells recovered on Day 10.5 of gestation from embryos resorbing in immune recipients were cytotoxic to $M$. caroli targets (Table 6), whereas cells isolated at this time from non-immune recipients were not (Croy et al., 1982). The cells isolated from immune mice were equally cytotoxic for target cells of transfer recipient or 3rd party genotypes. Lack of specificity for the presenting antigens is not shown by CD1 spleen cells sensitized to $M$. caroli cells in vitro (Croy, Rossant \& Clark, 1984) and this suggests that the 


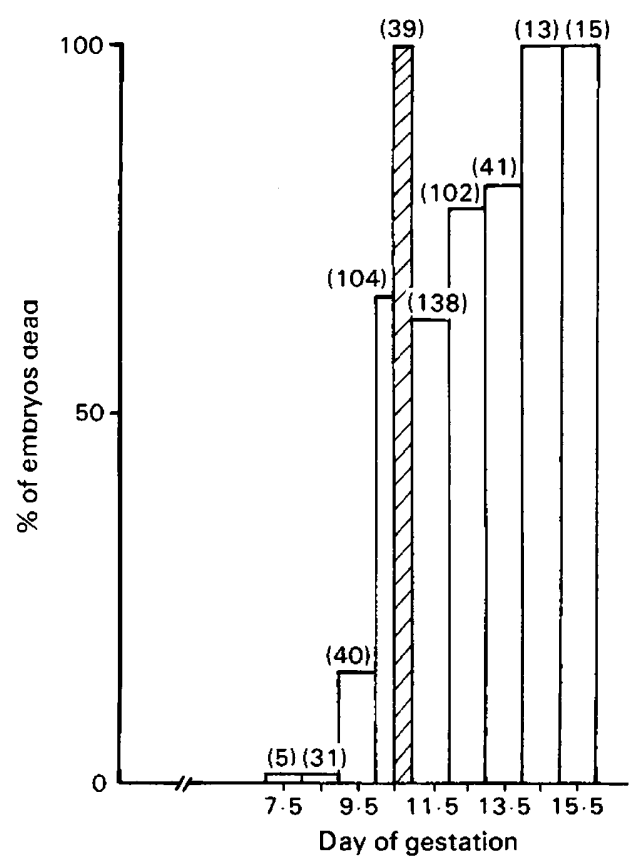

Text-fig. 1. Resorption of $M$. caroli embryos in non-immune (open bars) and immune (hatched bar) recipients. Numbers in parentheses represent the total number of implantation sites examined at each time point.

Table 6. Specificity of cytotoxic cells isolated from resorbing $M$. caroli embryos

\begin{tabular}{|c|c|c|c|c|c|c|c|c|}
\hline \multirow{2}{*}{$\begin{array}{c}\text { Gestational } \\
\text { age } \\
\text { (days) }\end{array}$} & \multirow{2}{*}{$\begin{array}{l}\text { Status } \\
\text { of } \\
\text { recipient }\end{array}$} & \multirow[b]{2}{*}{$\begin{array}{l}E: T \\
\text { ratio }\end{array}$} & \multicolumn{6}{|c|}{$\%{ }^{51} \mathrm{Cr}$ Release on target: } \\
\hline & & & $\begin{array}{c}M . \text { caroli } \\
\text { blasts }\end{array}$ & $\begin{array}{c}\mathrm{C} 3 \mathrm{H} \\
\text { blasts }\end{array}$ & $\begin{array}{l}\mathrm{CD1} \\
\text { blasts }\end{array}$ & P815 & $\begin{array}{l}\text { DBA } \\
\text { blasts }\end{array}$ & $\begin{array}{l}\text { YAC } \\
\text { cells }\end{array}$ \\
\hline $10 \cdot 5$ & Immune & $15: 1$ & $7 \cdot 2 \pm 0.7$ & $9.9 \pm 0.7$ & $8.4 \pm 0.6$ & - & - & - \\
\hline $12 \cdot 5$ & Non-immune & $10: 1$ & $8.5 \pm 0.8$ & $7 \cdot 3 \pm 0.4$ & - & $12 \cdot 3 \pm 0.5$ & - & - \\
\hline $12 \cdot 5$ & Non-immune & $15: 1$ & $8 \cdot 7 \pm 2 \cdot 2$ & - & - & $8.7 \pm 1.4$ & $7 \cdot 3 \pm 1.3$ & $8.7 \pm 0.7$ \\
\hline
\end{tabular}

*Values are mean \pm s.e.m., $n=3$ for cells from immunized mice and $n=6$ for cells from non-immune mice.

cytotoxic $\mathrm{T}$ cells present in resorbing embryos are not classical CTL but may be a novel cell class or an unusual mixture of cytotoxic cells.

The unusual pattern of lysis displayed by cells isolated from embryos resorbing in immune females could have resulted from the immunizations or may occur in cells isolated from embryos resorbing in unmanipulated females. Therefore, $M$. caroli blastocysts were transferred to nonimmune CDl recipients and cells were isolated from the resorbing embryos on Day 12.5 of gestation and assayed for cytotoxic specificity (Table 6). In two similar experiments we again demonstrated cells with a promiscuous pattern of cytotoxicity showing low but significant levels of cytotoxic activity against all targets. The absence of preferential lysis of the $M$. carolitargets in nonimmune and immune transfer recipients suggests that an identical cytotoxic process, not involving classical CTL, is occurring in embryos resorbing in both classes of recipients. Also, immunization can advance the time of appearance of these cytotoxic cells, but cannot significantly alter their pattern or level of reactivity. 


\section{Discussion}

This series of in-vivo experiments was performed to elucidate the role of the immune system in the midterm pregnancy failure of $M$. caroli embryos in the $M$. musculus uterus. The ideal hosts in which to test the hypothesis that immune responses directed specifically against $M$. caroli are the sole cause of death of $M$. caroli embryos would be females specifically unresponsive to $M$. caroli antigens, i.e. tolerant recipients. In such hosts cytotoxic responses to $M$. caroli antigens would not occur but all other immune, hormonal and physiological responses of pregnancy would remain normal. The procedure we employed to obtain xenogeneic tolerance was the production of embryonic chimaeras (Mintz \& Silvers, 1967; Phillips \& Wegmann, 1973; Matsunaga et al., 1980). Such $M$. musculus $\leftrightarrow M$. caroli chimaeras are viable and resemble allogeneic chimaeras in all properties examined to date (Rossant \& Chapman, 1983). Therefore, if immune responses directed against species antigens are important in the death of $M$. caroli embryos, $M$. caroli fetuses should survive in these recipients. However, $M$. caroli embryo failure was observed, leading to the conclusion that immune rejection is not the entire explanation for death of $M$. caroli embryos in either the chimaeric or $M$. musculus uterus. We were unable to demonstrate experimentally by skin grafting or by MLR and CTL assays (B. A. Croy, unpublished) that these chimaeras were actually species tolerant due to allogeneic variability within each of the parental species.

We also performed a series of transfers to immunodeficient recipients to determine whether survival of $M$. caroli embryos could be prolonged by selective depletion of immunocompetent cell populations. We observed a preferential loss of $M$. caroli fetuses over $M$. musculus fetuses in all of the immunodeficient recipients, and the time of death and gross pathological appearance of the resorbing embryos resembled that of $M$. caroli embryo failure in the uterus of normal $M$. musculus females. The necessity for participation of classic CTL effectors in $M$. caroli embryo death was eliminated by failure of $M$. caroli embryos in Cyclosporin A-treated recipients (Bunjes et al., 1982) and in $n u / n u$ recipients (Kindred, 1979). Death of $M$. caroli embryos in $n u / n u$ mice also eliminated any essential effector role for DTH responses (Kindred, 1979) while their death in $b g / b g$ mice eliminated NK cells as a principal effector mechanism (Roder \& Duwe, 1979). T cell-dependent antibody-mediated B cell responses are significantly reduced in $n u / n u$ mice (Croy \& Osoba, 1973), mice treated with Cyclosporin A (Bunjes et al., 1982) and mice treated with anti-Ia antibody (Waldor et al., 1984), making antibody-mediated embryonic failure unlikely. The only classes of immune effector cells not substantially reduced in any of the immunodeficient recipients were the macrophage and NC lineages (Stutman \& Cuttito, 1981), leaving open the possibility that these cells, which are not part of the specific immune effector system, may cause embryonic death. It is also still formally possible that failure of $\boldsymbol{M}$. caroli embryos was mediated by different graftdestroying mechanisms in each of the various immunodeficient hosts. We have therefore been unable to demonstrate in immunodeficient $M$. musculus and $M$. caroli $\leftrightarrow$ M. musculus chimaeric recipients that immune responses directed against $M$. caroli fetuses are the sole cause of pregnancy failure.

Immunization of recipients with $M$. caroli lymphocytes advanced both the time of $M$. caroli embryo death and the time of appearance of cytotoxic cells of the same non-specific type as found in non-immune recipients (Table 6). This indicated a clear involvement of the immune system in the actual process of destroying and resorbing the $M$. caroli fetuses. This was also illustrated by persistence of large, necrotic $M$. caroli fetuses in the recipients receiving Cyclosporin A. However, since fetuses still die in immunocompromised recipients, access of immune effector cells to the fetus may be a secondary consequence of some primary non-immunological failure.

If immunological events do not initiate failure of $M$. caroli embryos, what is the principal element determining their fate? Success or failure of $M$. caroli $\leftrightarrow M$. musculus chimaeras in the $M$. musculus uterus was previously shown to be determined by the genotype of trophoblast. $M$. musculus trophoblast allowed chimaeric (Rossant $e t$ al., 1982) and fully xenogenic fetuses (Rossant et al., 1983) to proceed to term in the $M$. musculus uterus. In this report, $M$. caroli embryos survived 
longest in chimaeras having the greatest $M$. caroli contribution (Table 2). That is, prolonged survival of $M$. caroli embryos was seen in the females in which $M$. caroli trophoblast would have the highest probability of matching with uterine cells of its own genotype at the implantation site. The results of transfers to chimaeras are thus consistent with the suggestion that the primary event in $M$. caroli embryo failure is incorrect interaction between $M$. caroli trophoblast and $M$. musculus uterine tissue.

This unsuccessful interaction may lead both to failure of growth and development of the xenogeneic $M$. caroli conceptuses and to failure of regulation of immunocompetent cells within the $M$. musculus uterus. Inadequate placental growth and function resulting from failure of trophoblast-uterine interactions would lead to fetal death from nutritional deficiency in immunodeficient and normal mice. Unsuccessful interaction between $M$. caroli trophoblast and $M$. musculus uterine tissue may also, however, lead to alteration in the immune status of the uterine environment. We have already shown that local suppressor cells are deficient at the sites of $M$. caroli embryo implantation in the M. musculus uterus (Clark et al., 1983). In normal or immunized recipients, embryonic failure would then be mediated or hastened by unregulated immune effector cells gaining access to the conceptus. Our current studies are directed towards definition of the defective interactions between $M$. caroli trophoblast and the $M$. musculus uterus.

These studies were supported by the Medical Research Council and the Natural Sciences and Engineering Research Council of Canada. J.R. is an E.W.R. Steacie Memorial Fellow and D.A.C. is an M.R.C. Scientist. We thank A. Chaput and L. DeRusha for technical assistance.

\section{References}

Ascher, N.L., Ferguson, R.M., Hoffman, R. \& Simmons, R.L. (1979) Partial characterization of cytotoxic cells infiltrating sponge matrix grafts. Transplantation 27, 254-259.

Beer, A.E. \& Billingham, R.E. (1976) The Immunobiology of Mammalian Reproduction. Prentice Hall, Englewood Cliffs.

Borel, J.F., Feurer, C., Magnee, D. \& Stahelin, H. (1977) Effects of the new anti-lymphocytic peptide Cyclosporin A in animals. Immunology 32, 1017-1025.

Brent, L., Hansen, J.A., Kilshaw, P.J. \& Thomas, A.V. (1973) Specific unresponsiveness to skin allografts in mice 1. Properties of tissue extracts and their synergistic effect with antilymphocytic serum. Transplantation 15, 160-171.

Bunjes, D., Hardt, C., Solback, W., Deusch, K., Rollinghoff, M. \& Wagner, H. (1982) Studies on the action of Cyclosporin $\mathrm{A}$ in the murine and human $\mathrm{T}$-cell response in citro. In Cyclosporin A, pp. 261-280. Ed. D. J. G. White. Elsevier Biomedical Press, Amsterdam.

Chutna, J., Holan, V. \& Hasek, M. (1981) Heterogeneity of tolerance to xenogeneic cells in mice inoculated at birth with rat cells. Cell. Immunol. 63, 193-197.

Clark, D.A., Slapsys, R.M., Croy, B.A. \& Rossant, J. (1983) Suppressor cell activity in uterine decidua correlates with success or failure of murine pregnancies. J. Immunol. 131, 540-542.

Croy, B.A. \& Osoba, D. (1973) Nude mice-a model system for studying the cellular basis of the humoral immune response. Cell. Immunol. 9, 306-318.

Croy, B.A., Rossant, J. \& Clark, D.A. (1982) Histological and immunological studies of post implantation death of Mus caroli embryos in the Mus musculus uterus. J. Reprod. Immunol. 4, 277-293.

Croy, B.A., Rossant, J. \& Clark, D.A. (1984) Recruitment of cytotoxic cells by ectopic grafts of xenogeneic, but not allogeneic, trophoblast. Transplantation 37, 8490.

Francescutti, L., Gambel, P. \& Wegmann, T. G. (1983) Injection chimaeras: a model for production of complete hemopoietic takeover in histoimcompatible adults. Transplantation Proc. 15, 1477-1479.

Frels, W.I., Rossant, J. \& Chapman, V.M. (1980) Intrinsic and extrinsic factors affecting the viability of Mus caroli $\times$ Mus musculus hybrid embryos. $J$. Reprod. Fert. 59, 387-392.

Green, C.J. (1975) Neuroleptanalgesic drug combinations in the anaesthetic management of small laboratory animals. Lab. Anim. 9, 161-178.

Kindred, B. (1979) Nude mice in immunobiology. Prog. Allergy 26, 137-238.

Manning, D.D., Reed, N.D. \& Schaffer, C.F. (1973) Maintenance of skin xenografts of widely divergent phylogenetic origin on congenitally athymic (nude) mice. J. exp. Med. 138, 488-494.

Matsunaga, T., Simpson, E. \& Meo, T. (1980) Allogeneic tolerance in embryo aggregation chimaeras studied by mixed lymphocyte culture and cell mediated lympholysis. Transplantation 30, 34-39.

McDevitt, H.O., Delovitch, T.L. \& Press, J.L. (1977) Functional and genetic analysis of Ia antigens. Cold Spring Harb. Symp. quant. Biol. 41, 489-496.

Mintz, B. \& Silvers, W.K. (1967) "Intrinsic" immunological tolerance in allophenic mice. Science, $N . Y .158$,

1484-1487. 
Pantelouris, E.M. (1968) Absence of thymus in a mouse mutant. Nature, Lond. 217, 370-371.

Perry, L. \& Green, M.I. (1982) Conversion of immunity to suppression by in vivo administration of I-A subregion specific antibodies. J. exp. Med. 156, 480491.

Phillips, M.S. \& Wegmann, T.G. (1973) Active suppression as a possible mechanism of tolerance in tetraparental mice. J. exp. Med. 137, 291-300.

Roder, J.C. \& Duwe, A.K. (1979) The beige mutation in the mouse selectively impairs natural killer cell function. Nature, Lond. 278, 451-453.

Rossant, J. \& Chapman, V.M. (1983) Somatic and germline mosaicism in interspecific chimaeras between Mus musculus and Mus caroli. J. Embryol. exp. Morph. 73, 193-205.

Rossant, J. \& Frels, W.I. (1980) Interspecific chimaeras in mammals: successful production of live chimaeras between Mus musculus and Mus caroli. Science, N.Y. 208, 419-421.

Rossant, J., Mauro, V.M. \& Croy, B.A. (1982) Importance of trophoblast genotype for survival of interspecific murine chimaeras. J. Embryol. exp. Morph. 69, $141-149$.

Rossant, J., Croy, B.A., Clark, D.A. \& Chapman, V.M. (1983) Interspecific hybrids and chimeras in mice. $J$. exp. Zool. 228, 223-233.
Ryffel, B. (1982) Experimental toxicological studies with Cyclosporin A. In Cyclosporin A, pp. 45-75. Ed. D. J. G. White. Elsevier Biomedical Press, Amsterdam.

Sharp, A.K. \& Colston, M.J. (1984) Elevated macrophage activity in nude mide. In Immune-deficient Animals, pp. 44-47. Ed. B. Sordat. S. Karger, Basel.

Streilein, J.W. \& Gruchalla, R.S. (1981) Analysis of neonatally induced tolerance of $\mathbf{H}-2$ alloantigens. 1 . Adoptive transfer indicates that tolerance of Class I and Class II antigens is maintained by different mechanisms. Immunogenetics 12, 161-173.

Stutman, O. \& Cuttito, M.S. (1981) Normal levels of natural cytotoxic cells against solid tumours in NKdeficient beige mice. Nature, Lond. 290, 254-257.

Waldor, M.K., Hardy, R.R., Hayakawa, K., Steinman, L., Herzenberg, L.A. \& Herzenberg, L.A. (1984) Disappearance and reappearance of $\mathbf{B}$ cells after in vivo treatment with monoclonal anti-I-A antibodies. Proc. natn. Acad. Sci., U.S.A. 81, 2855-2858.

White, D.J., Plumb, A.M., Pawelec, G. \& Brons, G. (1979) Cyclosporin A: An immunosuppressive agent preferentially active against proliferating $\mathrm{T}$ cells. Transplantation $27,55-58$.

Whittingham, D.G. \& Wales, R.G. (1969) Storage of twocell mouse embryos in vitro. Aust. J. biol. Sci. 22, 1065-1068.

Received 7 September 1984 